\title{
THE USE OF HERBERT CANNULATED BONE SCREW IN THE TREATMENT OF MANDIBULAR FRACTURES (A CLINICAL AND RADIOGRAPHIC STUDY)
}

\author{
Yehia A. El-Mahallawy ${ }^{1} B D S$, Sherief H El-Ghamrawey ${ }^{2} P h D$, Mervat M. Khalil ${ }^{2} P h D$.
}

\begin{abstract}
INTRODUCTION: Maxillofacial trauma is in querulous expansion by clinical and biomechanical studies in order to enhance the wellestablished techniques and to utilize new materials, all are directed towards the reduction in the immobilization period and enhancement of the rigid fixation. Since 1984 the cannulated Herbert Bone Screw (HBS) proves to be a successful mean of fracture fixation in various fields of orthopaedic surgery, nonetheless with no sufficient evidence about its performance in the maxillofacial trauma field.

OBJECTIVES:The aim of the study was to evaluate clinically and radiographically the performance of HBS in the treatment of mandibular fractures.

MATERIALS AND METHODS: Eleven patients with non-comminuted recent mandibular fracture were treated using Herbert bone screw. Clinical follow up was conducted after 24-hours, one week, four weeks, six weeks and twelve weeks. Also, a radiographic investigation was performed immediately postoperative and after twelve weeks to estimate the mean bone density across the fracture line.

RESULTS: By the end of the follow up period, all cases showed normal lower lip sensation, normal occlusal and intercuspal relation, a statistically significant (P value $<0.001$ ) decrease in level of pain intensity score based on the Visual Analogue Scale (VAS) and an uneventful wound healing with no records of developed infection. Mean bone density after twelve weeks showed a statistically significant $(\mathrm{p}<0.001)$ increase in its values when compared to the immediately postoperative values.

CONCLUSIONS: This study deduced that the use of Herbert screws results in a predictable and satisfactory outcome, in terms of achieving uneventful wound healing and high postoperative mean bone density values.

KEYWORDS: Mandibular fracture, Herbert Bone Screw, Cannulated Screw, Traction Osteosynthesis.
\end{abstract}

1. Instructor at the Oral and Maxillofacial Surgery Department, Faculty of Dentistry, Alexandria University, Alexandria Egypt.

2. Professor of Oral and Maxillofacial Surgery Department, Faculty of Dentistry, Alexandria University, Alexandria Egypt

\section{INTRODUCTION}

The main intent of mandible fractures management should be the patient return to the pre-existing state of function and aesthetics (1). Maxillofacial trauma management has always been a challenging subset for the maxillofacial surgeons and in which various clinical and biomechanical studies are continuously being performed in order to improve the established techniques and materials that have been excelled over the years. These approaches have ranged from closed reduction with maxillomandibular fixation (MMF), to open reduction with wire osteosynthesis, to open reduction with rigid or functionally stabilized internal fixation (2)

The Arbeitsgemeinschaft für Osteosynthesefragen/ Association for the Study of Internal Fixation (AO/ASIF) was formed in the late 1950's to handle debates on internal fixation of fractures (3).

Rigid internal fixation must counterbalance all forces developed during functional loading of the mandible which provides three-dimensional stability across the fracture line that decreases the subjected strain and encourages primary bone healing (4).

Traction osteosynthesis was introduced in the maxillofacial region by Brons and Boering in 1970 (5) as a rigid fixation scheme for the management of mandibular fracture, they immobilize the fractured segments along with producing constant compression along the fracture line. Traction osteosynthesis systems work provides the greatest rigidity of all fixation techniques, especially in oblique fractures.

In 1984, Herbert and Fisher (6) proposed a new method for rigid fixation to manage scaphoid bone fracture, from this point forth, it demonstrated to be a successful mean of providing rigid internal fixation between fracture segments in various terrains of orthopaedic surgery, especially that of small bones.

While the indexed contemporary literature demonstrates the superiority of HBS in orthopaedic fracture treatment, it falls short in providing sufficient data about the prospective outcomes of HBS fixation in maxillofacial trauma. Henceforth, this study was conducted to evaluate the aftermath of HBS fixation in mandibular fractures.

\section{MATERIALS AND METHODS}

This was a Prospective Clinical and Radiographic study, that was conducted after granting the ethical clearance from the Research Ethics Committee, Faculty of Dentistry, Alexandria University.

\section{Patients}

Eleven patients stricken by mandibular fracture have been selected from the cases admitted to the Emergency Ward of Alexandria University Teaching Hospital in the period between November 2016 and June 2017. All the selected subjects were adults with no gender predilection suffering from recent, uninfected, non-comminuted, unfavourable fracture that demands open reduction and internal fixation mandibular fracture, including symphysis, para symphysis, body and angle, and excluding those with systemic diseases that could have interfered with healing. All patients signed an informed consent before embarking on the surgical operation to manage the fracture with open reduction and direct internal osteosynthesis utilizing the traction osteosynthesis principle applying Herbert Bone Screw (HBS). 


\section{Materials}

The Herbert screws are a compressive cortical cannulated Titanium screw with differential pitch pattern of threads at both ends and a blank smooth central shaft (JEIL Medical Corporation Company: Seoul, Korea) (Figure 1).

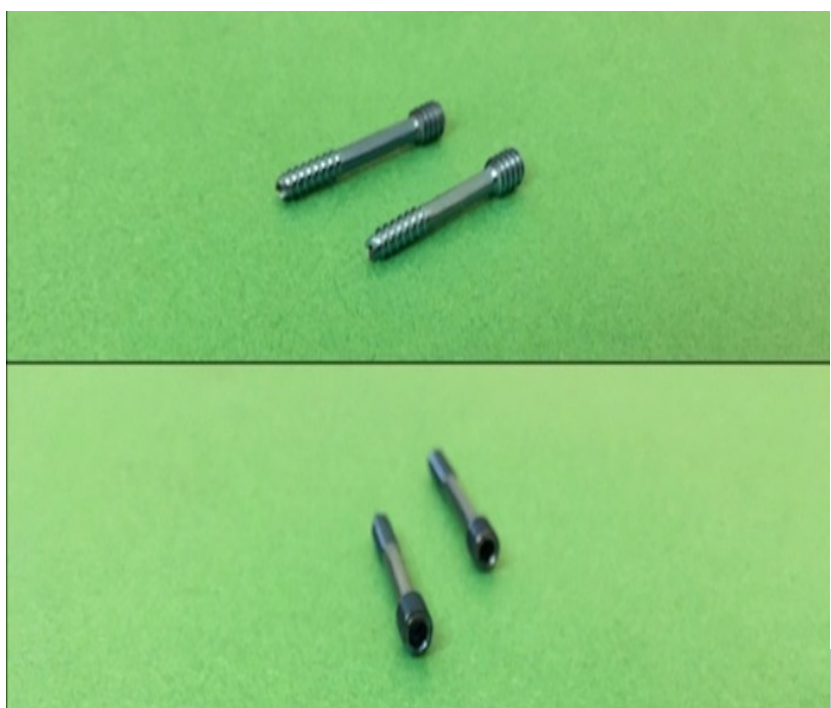

Figure (1): Showing the Herbert cannulated Bone screw

The leading end threads are of the reverse buttress type, they are longer in length and with a smaller diameter than those at the trailing end which are standard V-shaped. The utilized screw had a shaft diameter of $1.25 \mathrm{~mm}$, a cortical head diameter of $2.3 \mathrm{~mm}$ and a 2.0 cancellous head, it's length ranged from 10 to $35 \mathrm{~mm}$.

\section{Methods}

\section{I) Pre-operative assessment and examinations}

A detailed history taking was performed to collect the preoperative the demographic data of the patients, including name, age, gender, occupation, address, onset and etiology of the fracture.

Followed by a thorough clinical, intraoral and extraoral, examination was performed to record swelling, ecchymosis, deformity of the bony contour and the occlusal plane, ecchymosis and fracture haematoma in the buccal and lingual sulci, soft tissue laceration and deviation of the mandible during opening and closing by inspection and to detect the site of tenderness, step defects, alteration of bony contour and bony crepitus by palpation.

A preoperative computerized tomogram (CT) was obtained to show the extent of fracture line, reveal the degree and direction of displacement, show the relation of teeth involved in the fracture line, help in the localization of inferior alveolar nerve and to measure the width of the fractured bone segments (Figure 2). The mean bone density at the fracture site was calculated by measuring bone density at 6 points in the vicinity of the fracture lie using CT software then taking their averages to determine the preoperative, immediate postoperative and 3 months' postoperative mean bone density. All of the measurements were in Hounsfield Units (HU).

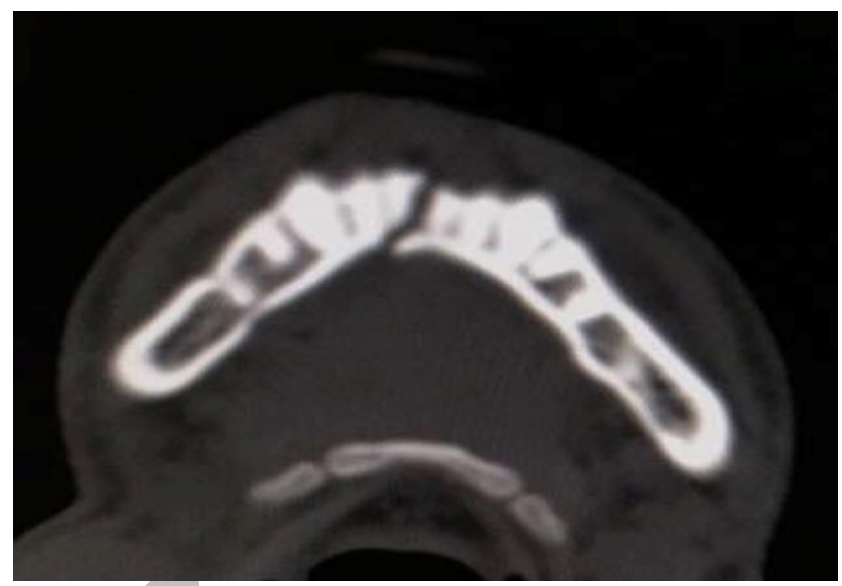

Figure (2): Showing Preoperative CT-scan axial cut of mandibular symphyseal fracture

\section{II) Surgical phase}

Prophylactic antibiotic therapy was administered preoperatively in the form of Cefotaxime $1 \mathrm{gm} / 12$ hours (Cefotax, E.I.P.I.C.O, Egypt) intravenously to prevent postoperative infection. All of the patients were treated under general anaesthesia using nasal intubation. The surgical site is swabbed using povidone iodine solution (Betadine 7.5\%; Purdue Products L.P), then draped with sterile towels.

The occlusion was secured with temporary IMF and the fracture line was exposed and manually reduced. Fractures anterior to the mental foramen were exposed via intraoral vestibular degloving approach by making a curvilinear incision $3 \mathrm{~mm}$ apical to the mucogingival junction. Fractures in the mandibular angle were exposed using extraoral submandibular approach using a $4 \mathrm{~cm}$ long skin and subcutaneous incision placed $1.5-2 \mathrm{~cm}$ below the inferior border of the mandible. Exposure of the fracture site was obtained by standard layered dissection through mucosa, mentalis muscle, and the periosteum in the intraoral vestibular degloving approach, and through platysma muscle, investing layer of the deep cervical fascia, pterygomasseteric sling and periosteum in the extraoral submandibular approach. This was followed by reduction of the fractured segments, as they were held in position and confirmed visually by verifying the alignment of the buccal cortex and inferior border.

A $0.8 \mathrm{~mm}$ Kirschner guide wire was drilled and tapped into the opposite cortex of the distal fracture segment. The depth of the K-wire was measured using a depth gauge to determine the length of the screw to be utilized. A $2 \mathrm{~mm}$ cannulated spiral drill was used under the guidance of the K-Guide to make the osteotomy, followed by Herbert Bone Screw placement, with the aid of the cannulated torque shank screwdriver (Figure 3).

In case of a symphyseal or a parasymphyseal fracture, a second screw was placed in the similar manner and direction to avoid rotation of the compressed fracture line in the area anterior to the mental foramina. The occlusion of all patients was checked by releasing the temporary IMF closing wires to confirm stable and reproducible occlusion. The incision sites were irrigated with normal saline solution, and wound closure in layers was performed, using Vicryl suture material (Johnson \& Johnson Int. European Logistics Centre, Belgium) (Figure 4). 


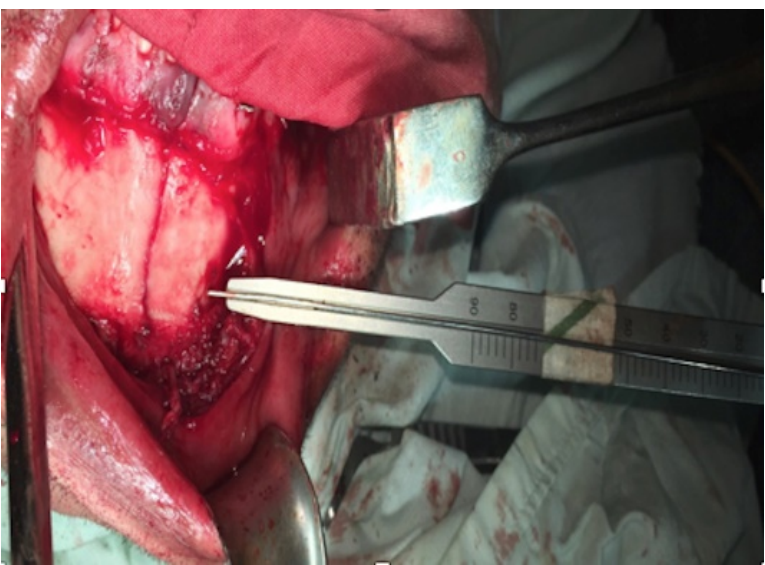

Figure (3): Showing the depth gage on the top of the inserted KGuide wire.

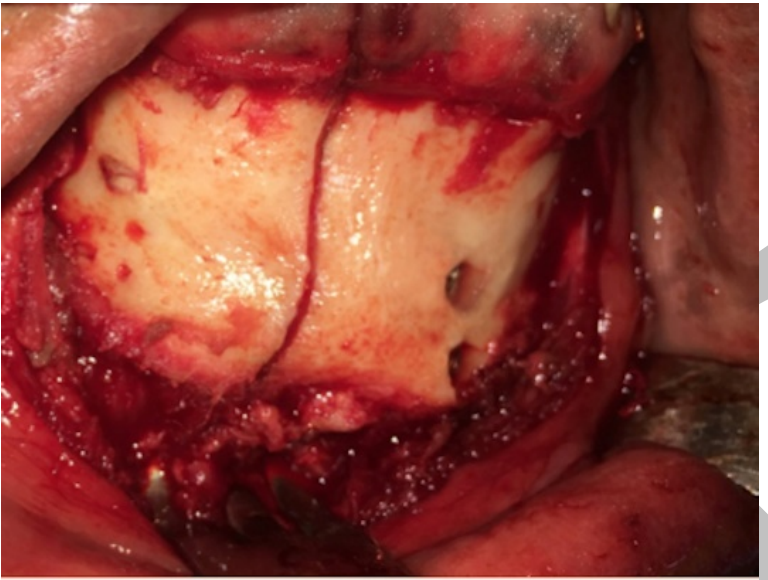

Figure (4): Showing two Herbert Bone Screw in place.

\section{III) Post-operative phase}

All patients received oral antibiotics in the form of Amoxicillin $500 \mathrm{mg}+$ Clavulanic acid $125 \mathrm{mg}$ (Augmentin 625 mg; GlaxoSmithKline, UK) daily every 8 hours for 57 days after discharge. Analgesic and anti-inflammatory medication in the form of diclofenac potassium $50 \mathrm{mg}$ tablets (Cataflam50 mg, Novartis, Switzerland) was given daily every 8 hours for five days, and the patient were instructed to follow a soft diet for one month with careful and meticulous oral hygiene.

\section{IV)Follow up phase}

\section{A-Clinical evaluation:}

A postoperative clinical assessment was executed after 24hours, one week, four weeks, six weeks and twelve weeks. A postoperative clinical evaluation for pain (assessed by visual analogue scale), state of occlusion, mouth opening (assessed by measuring inter-incisal distance in $\mathrm{mm}$ ), sensory nerve function and wound healing was performed,

\section{B- Radiographic evaluation:}

A postoperative radiographic appraisal was performed using an immediate postoperative CT-scan to assess the adequacy of fracture line reduction from buccal and lingual perspectives, then another scan was taken after three months to show fracture healing progression and for radiodensitometric estimate of the mean bone density at the fracture line in comparison with the immediate postoperative scan (Figure 5 \& 6).

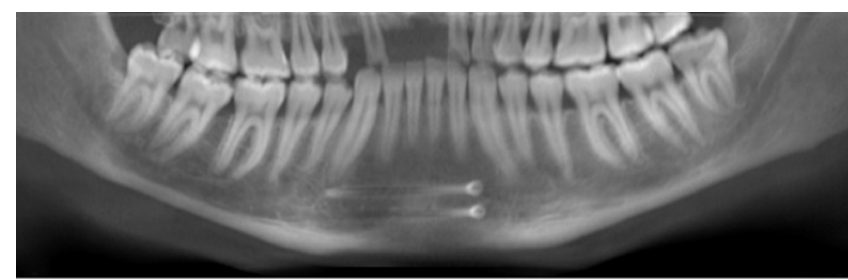

Figure (5): Showing Postoperative panoramic view of Herbert Bone Screw in situ at twelve weeks.

\section{Statistical analysis}

All of the recorded data were documented, tabulated and statistically analysed utilizing the IBM SPSS software package version 20.0. (Armonk, NY: IBM Corp) (7). Qualitative data were presented by number and percent, while quantitative data were described using range (minimum and maximum), mean, standard deviation and median. The Kolmogorov-Smirnov test was used to verify the normality of data distribution, where the ANOVA with repeated measures test was used for normally distributed quantitative variables, to compare between more than two periods or stages, and the Friedman test for the abnormally distributed quantitative variables. The significance of the obtained results was judged at the $5 \%$ level $(\mathrm{P}<0.05)(8)$.

\section{RESULTS}

\section{Demographic data}

All of the eleven included patients involved in this study were treated with open reduction and direct internal skeletal fixation utilizing Herbert Bone Screw traction osteosynthesis. They consisted of nine males (81.8\%) and two females (18.2\%); with a ratio of $4.5: 1$. Their age ranged from 18 to 54 years with a mean of $29.0 \pm 9.74$ years. The most common etiological factor was found to be claimed falls $(63.6 \%, \mathrm{n}=7)$; the remaining fractures were the result of Road Traffic Accidents (RTA) $(27.3 \%, \mathrm{n}=3$ ), and sports-related injury $(9.1 \%, \mathrm{n}=1)$ (Table 1$)$.

Table (1): Showing the distribution of the studied cases according to demographic data $(n=11)$.

\begin{tabular}{|l|l|}
\hline \multicolumn{1}{|c|}{ Characteristic } & \multicolumn{1}{c|}{$\%(\mathbf{n}=\mathbf{1 1})$} \\
Male & $81.8 \%(\mathrm{n}=9)$ \\
female & $18.2(\mathrm{n}=2)$ \\
\hline Age (years) & $18.0-54.0$ \\
Min. - Max & $29.0 \pm 9.74$ \\
Mean \pm SD & 28.0 \\
Median & \\
\hline $\begin{array}{l}\text { Fall } \\
\text { RTA } \\
\text { Sports related injuries }\end{array}$ & $63.6 \%(\mathrm{n}=7)$ \\
\hline $\begin{array}{l}\text { Yssociated fracture } \\
\text { No }\end{array}$ & $27.3 \%(\mathrm{n}=3)$ \\
\hline
\end{tabular}


Out of the eleven patients in this study; five patients had mandibular angle fracture (45.5\%) (three left side fractures and two in the right side), and six patients had fracture anterior to the mental foramen (54.6\%), four symphyseal (36.4\%) and two parasymphyseal fracture (18.2\%) (one in each side).Eight patients $(72.7 \%)$ had other associated contralateral fractures, the most common combination was symphyseal-subcondylar (27.3\%, $\mathrm{n}=3$ ) (Table 1).

\section{Clinical data}

All of the studied cases were monitored for 12 weeks postoperatively. Across the follow up period, all the cases experienced a decrease in the level of pain intensity score based on the Visual Analogue Scale (VAS). At 24h postoperative follow up the mean value of pain score was $5.0 \pm 1.10$, which decreased at the first postoperative week to $3.82 \pm 1.08$ with a percentage of change of $22.88 \pm 19.16$ $\%$, which is statistically not significant ( $\mathrm{P}$ value $=0.225$ ). At the fourth postoperative week, the mean recorded score was $1.73 \pm 0.90$. The decrease in the pain was found to be statistically significant when compared with the $24 \mathrm{~h}$ postoperative values $(\mathrm{P}$ value $=0.002)$, and percentage of change of $66.52 \pm 12.42 \%$. while at the sixth postoperative week the mean pain value was $0.82 \pm 0.75$, showing an $83.48 \pm 14.27 \%$ decrease from the $24 \mathrm{~h}$ postoperative values, with a statistically significant difference ( $\mathrm{P}$ value $<0.001$ ). No pain was recorded at twelve weeks postoperative follow up among all the cases. The decrease in pain intensity across the follow up period was statistically significant (P value $<0.001)$.

The occlusal examination showed a normal occlusal and intercuspal relation in all of the cases. There was no need for selective grinding in any case during the follow up period.

Out of the six patients with fracture anterior to the mental foramen, $33.3 \% \quad(n=2)$ showed impaired postoperative lower lip paraesthesia at the first follow-up assessment (1 week). By the end of the follow up period, both cases regained normal sensation in the lower lip. While all of the five patients with angle fracture reported normal lower lip sensation objectively and subjectively. 9.1\% (n=1) of the cases showed postoperative wound dehiscence at first postoperative week (a case with Left Parasymphyseal fracture), which was treated by irrigation, margin debridement and healing by secondary intention without the need of re-suturing. Infection wasn't encountered in any of the cases.

\section{Radiographic data}

Regarding the five mandibular angle cases, the mean preoperative bone density was $845.92 \pm 120.32 \mathrm{HU}$. When compared to the mean immediate postoperative records (982.89 $\pm 164.31 \mathrm{HU})$, it showed a $16.07 \pm 8.04 \%$ increase from the preoperative values, with a statistically significant difference between the two records $(p=0.016)$. While the mean three months' postoperative bone density (1156.40 $\pm 118.70 \mathrm{HU})$ revealed a statistically significant gain in bone density when compared to the preoperative values $(\mathrm{p}<0.001)$, with a percentage of change of $37.51 \pm$ $9.19 \%$, also when compared to the immediately postoperative records $(\mathrm{p}=0.002)$ (Table 2$)$.

The mean preoperative bone density of the six cases with fractures anterior to the mental foramen was $957.0 \pm 36.05 \mathrm{HU}$, while they recorded a mean value of $1023.01 \pm 45.24 \mathrm{HU}$ in the immediately postoperative scans, with a $6.90 \pm 2.65 \%$ increase from the preoperative values, which is a statistically significant difference between the two records $(p=0.001)$. in the scans taken after 3 months, the mean bone density value was $1156.29 \pm 64.05 \mathrm{HU}$. The increase in mean bone density was found to be statistically significant when compared to the preoperative values $(p<0.001)$, with a percentage of change of $20.79 \pm 3.55 \%$, also when compared to the immediately postoperative records $(\mathrm{p}=0.001)$ (Table 3$)$.

Table (2): Showing the descriptive analysis of the mandibular angle cases according to the mean bone density

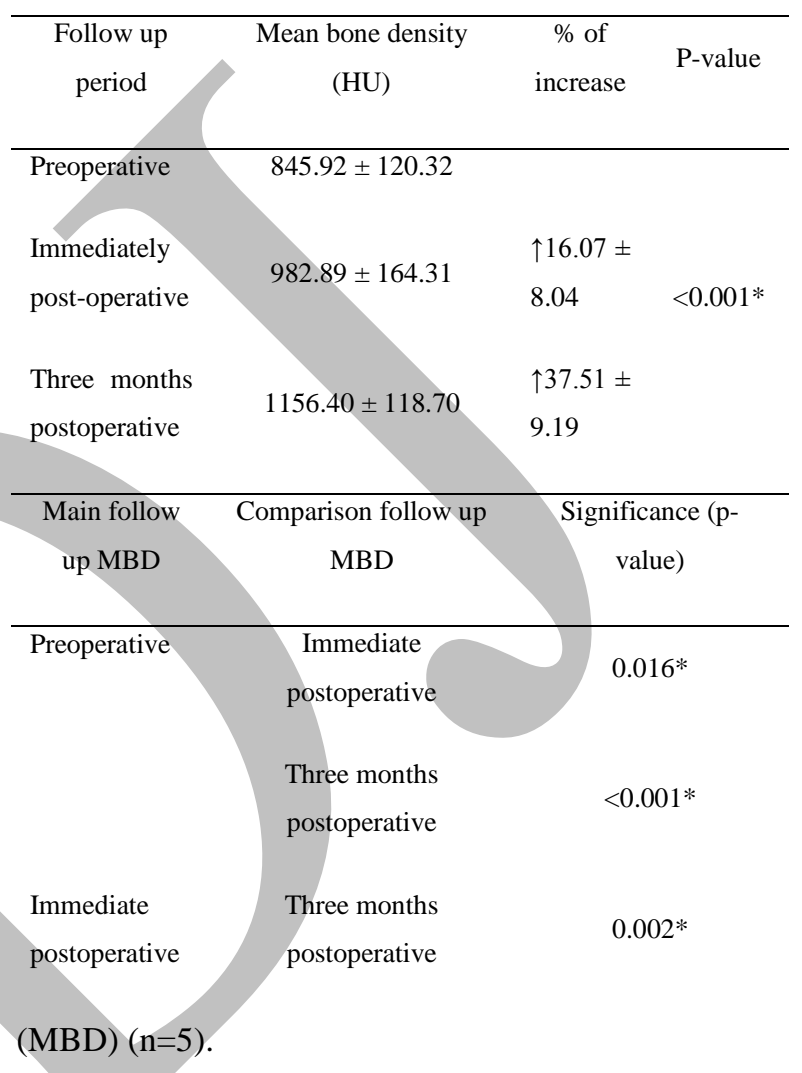

Table (3): Showing the descriptive analysis of the cases anterior to the mental foramen according to the mean bone density $(n=6)$.

\begin{tabular}{|c|c|c|c|c|}
\hline $\begin{array}{l}\text { Number of new } \\
\text { blood vessels }\end{array}$ & $\begin{array}{l}\text { AM grafted } \\
\text { wounds }\end{array}$ & $\begin{array}{l}\text { Control non- } \\
\text { grafted wounds }\end{array}$ & $\mathbf{t}$ & $\mathbf{p}$ \\
\hline \multicolumn{5}{|l|}{ Group I ( $1^{\text {st }}$ week $)$} \\
\hline Min. - Max. & $39.0-54.0$ & $30.0-39.0$ & \multirow{3}{*}{$2.842^{*}$} & \multirow{3}{*}{$0.047^{*}$} \\
\hline Mean \pm SD & $45.60 \pm 6.66$ & $34.80 \pm 3.27$ & & \\
\hline Median & 44.0 & 35.0 & & \\
\hline \multicolumn{5}{|l|}{$\begin{array}{l}\text { Group II ( } 2^{\text {nd }} \\
\text { week) }\end{array}$} \\
\hline Min. - Max. & $26.0-31.0$ & $20.0-26.0$ & \multirow{3}{*}{$3.592^{*}$} & \multirow{3}{*}{$0.023^{*}$} \\
\hline Mean \pm SD. & $28.60 \pm 2.07$ & $23.20 \pm 2.28$ & & \\
\hline Median & 29.0 & 24.0 & & \\
\hline \multicolumn{5}{|l|}{$\begin{array}{l}\text { Group III (3 } \\
\text { week) }\end{array}$} \\
\hline Min. - Max. & $11.0-22.0$ & $5.0-13.0$ & \multirow{3}{*}{2.648} & \multirow{3}{*}{0.057} \\
\hline Mean \pm SD & $17.60 \pm 4.28$ & $8.80 \pm 3.19$ & & \\
\hline Median & 19.0 & 8.0 & & \\
\hline
\end{tabular}




\section{DISCUSSION}

Management of mandibular fractures is one of the most demanding and continuously evolving fields that maxillofacial surgeon deals with. Regaining premorbid occlusion and providing immediate uncompromised functional stability are the main points that must be put in mind during mandibular fracture management (9).

The descriptive analysis of the demographic information from the patients randomly selected in this study according to the inclusion and exclusion criteria unveiled a mean cases age to be $29.0 \pm 9.74$ years, ranging from 18 to 54 years, with male prevalence of $81.8 \%(n=9)$ and male to female ratio of $4.5: 1$. These results are in accordance with those of most of the other studies (10-11). Mabrouk et al in 2014 (12) explored the epidemiology of maxillofacial fracture in Egypt and found that people around the mean age of 25.7 years were significantly more likely to sustain facial fractures, which is lower than this study results but still remaining in the same decade of life. Also, they deduced a male to female ratio of 5.7:1 which is higher than this study. Melek and Sharara in 2016 (13) declared a lower mean age (25.56 \pm 14.04 years) and almost identical male to female ratio $(4.5: 1)$ as our results.

It is thought that this correlation reflects the cultural and vocational differences in our eastern community, where males are more engaged in high-risk jobs and outdoor daily life risks, leading to higher probability of physical injuries which might prompt facial wounds. Also, individuals in the third and fourth decade of age are in their most energetic span of their life's, and they are more likely to be involved in outdoor activates, altercations, hazardous sports and high-speed driving when compared to other segments of the population. Furthermore, they represent a large extent of Egypt's inhabitants (12).

There is an explicit accord among authors that main causes of maxillofacial fractures all over the world, especially in developing countries, are Road Traffic Accidents (RTA), assaults, falls, and sports-related injuries. $(12,14-16)$. That's owing to the irresponsible driving behaviour, poor road conditions and their lack of maintenance, and inadequate road safety regulations enforcement. Nonetheless, this study came out with claimed falls as the most common etiological factor for mandibular fracture, representing 63.6\% $(n=7)$, followed by RTA $(27.3 \%, n=3)$, while only $9.1 \%(n=1)$ suffered a sportsrelated injury. Siber et al (17) reached out the same outcome, where falling down represented $65 \%$ of all the mandibular fracture cases.

Across the follow up period, all the cases experienced a decrease in the level of pain intensity score based on the Visual Analogue Scale (VAS), where the mean score at $24 \mathrm{~h}$ postoperative follow up was $5.0 \pm 1.10$, which is equivalent to the baseline level of the moderate subjective pain sensation. This value showed an insignificant decrease $(p=0.225)$ to become $3.80 \pm 1.08$ at the first postoperative follow up, then a significant difference $(p=0.002)$ at the second postoperative follow up $(1.73 \pm 0.90)$. The overall decline in the recorded pain scores across the follow up period was statistically significant $(p<0.001)$. This is a rational assumption considering that adequate stabilization of the bone fragments across the fracture line will eliminate pain and discomfort of the patient.

Bhatnagar et al in 2013 (18) and Kotrashetti and Singh in 2017 (19) showed a similar statistically significant decrease in the documented pain scores across the follow up span. Kotrashetti showed a more rapid decrease in the cases treated with HBS than in those treated with the conventional lag screw, while Bhatnagar recorded lower pain scores in patients treated with lag screw than those managed with miniplates. It may be presumed that the less the amount of drilling required and the less the amount of hardware utilized to achieve stable fixation, the less score of pain will be recorded from the patient.

Concerning the state of the postoperative occlusion, all the subjects exhibited a normal intercuspal centric occlusion relation and there was no need for elastic traction, selective grinding or even selective extraction in any case. Many authors came out with the same outcome (20-22). However, Kotrashetti and Singh in 2017 (19) registered a 26.7\% ( $n=2)$ of cases with postoperative malocclusion that required elastic traction for 15 days to regain their premorbid occlusion.

The study was conducted on six cases with symphyseal or parasymphyseal fractures (anterior to the mental foramen), meticulous intraoperatively nerve identification and skeletonization from its housing sheet were performed along to relieve tension allowing its gentle tension free retraction. Nonetheless, 33.3\% $(n=2)$ of the cases showed sensory impairment in the first follow up period. Both cases regained normal lower lip sensation by the end of the twelve weeks follow up period. Kotrashetti and Singh in 2017 (19) was faced with similar cases percentage which persisted to the second follow up period but eventfully turned back to normal by the end of the follow up period. Boffano et al in 2014 (23) reported a $24.3 \%$. A retrospective study done by Schenkel and Jacobsen in 2016 (24) reported that one-third of the population suffered from postoperative paraesthesia, however with a $70 \%$ of the affected cases returning to normal. Owing to the slow neural regeneration, extending the follow up period of Schenkel and Jacobsen study might have yielded in a $100 \%$ recovery. Sustaining a postoperative paraesthesia depends mainly on the degree of the preoperative displacement and aggressive fracture manipulation rather than due to the nerve close proximity to the fixation hardware

The remaining five posterior angle cases reported normal postoperative lip sensation during the early follow up period. That is in accordance with Balasubramanian et al in 2014 (25) and Chhabaria et al in 2014 (26), while Guimond and Johnson in 2005 (27) observed a sensory deficient in $25 \%$ of the cases which regained normal sensation by the end of the three months follow up period.

Neither of our patients suffered from a postoperative infection. They were all given prophylactic preoperative antibiotics and were put on a postoperative antibiotic regime for five days. Shridharani et al in 2015 (28) noted as low as $1.1 \%$ of postoperative infection following ORIF when the subjects were put under postoperative antibiotic course. Following a strict infection control protocol and aseptic intraoperative techniques have their role in the reduction of the number of cases with postoperative infection.

We recorded that $9.1 \%(n=1)$ of the cases experienced postoperative wound dehiscence, but with no accompanying hardware exposure. The reported case was that of parasymphyseal fracture, where a degloving incision was utilized to expose the fracture line. The dehiscence was noted in the first postoperative week, daily irrigation was 
performed and it healed with secondary intention with no need of re-suturing at the end of the first month with no effect on the fracture stability. Saman et al in 2014 (29) reported 4.7\% while Ellis in 2012 (30) reported a lower $1.2 \%$ percentage $(n=2)$.

Multiple factors play role in dehiscence development, including the strong mentalis muscle pull, poor suturing technique, contamination, infection, smoking etc. To counteract the pulling effect of the mentalis muscle, thus decreasing the incidence of dehiscence and ptosis of the lip, the muscle is reattached to its origin by at least three deep resorbable sutures before normal mucosal closure. Ellis noted a lower wound dehiscence percentage in cases where lag screw was utilized than in those managed with miniplates (3.4\%). This debated the external placement of the bone plates versus the internal positioning of the hardware in the traction osteosynthesis systems. Where the internal positioning may profit from avoiding hardware exposure with a higher chance of achieving wound healing with secondary intention.

An extraoral submandibular incision was utilized in all of the five cases with angle fracture, all of which healed uneventfully without dehiscence. Pattar et al in 2014 (31) achieved similar result.

Regarding the postoperative radiographic appraisal and the mean bone density, the five cases with mandibular angle fractures, a statistically significant increase in mean bone density was recorded from the preoperative measure to the immediate postoperative measure $(\mathrm{p}=0.016)$, and from the immediate scan to the three-month scan $(p=0.002)$, which is coherent with fracture healing progress.

This didn't change in the six cases with fractures anterior to the mental foramen, where bone density increases significantly $(\mathrm{p}=0.001)$ in the immediate postoperative scan with a percentage of change of $6.90 \pm$ $2.65 \%$, and $20.79 \pm 3.55 \%$ increase in the twelve-week scan $(\mathrm{p}<0.001)$.

Achieving a predictable primary bone healing and rapid early return to function can only be accomplished with an absolute rigid fixation of the fractured segments, minimizing intrafragmentary strain and avoiding the probability of infection. Osteosynthesis relaying on the axial compression tends to achieve more rapid bone healing than non-compressive systems (25). Furthermore, Kotrashetti and Singh in 2017 (19) announced a higher bone isodensity values when HBS is used than with Lag screw, indicating a significantly faster healing.

Traction osteosynthesis systems, that rely on axial compression, are proven to promote a surpassed rigidity and great compression across the entire length of the fracture line, hence a briskly bone healing with early functional stability (32).

Several authors reported the use of lag screw for rigid ORIF of mandibular angle fractures but with strict adhesion to traction osteosynthesis systems inclusion criteria, as they rely entirely on compression of bone fragments, thus requiring a solid stable uninterrupted bone buttresses at both sides of the fracture line, whereas compression across comminuted or missing bone fragments may come forth with segments overriding with shortening of the fracture gap and displacement of intervening bone fragments which are followed with occlusal derangement $(19,25,32)$.

We opted to use a solitary HBS for fracture segments traction and stabilization. The selected point of entry was approximately $12-15 \mathrm{~mm}$ anterior to the fracture, in this manner, a sound bony buttress will remain in front of the fracture line allowing proper fixation by the thrilling head of the screw. With attention not to exaggerate the drilling superior-inferior angulation to avoid weakening of the proximal fractured segment while protecting the integrity of the inferior alveolar neurovascular bundle, thus the screw is multi-planer inside the medulla of the ramus and it neutralizes the functional forces at the tension upper border zone. In five cases of this study, outstanding rigidity and no interfragmentary mobility were recorded without the need of tapping the cortex of the posterior border of the ramus.

Aside from its distinct advantage over the miniplate system in the ability of achieving great compression between the fragments to promote healing and to stabilize the entire length of the fracture without causing facial asymmetry as a result of bulky compressive plates, utilizing lag screw in the management of angle fracture requires less hardware making it more cost-effective than bone plating, with no concerns about plate adaptation and multiple fixation screws drilling. Also, lower incidence of infection is reported due to the absence of interfragmentary mobility.

Schaaf et al in 2011 (34). came out with the conclusion that miniplate fixation resulted in a wider fracture gap, especially in the region of the lower margin of the mandible, in comparison to traction osteosynthesis fixation.

Ellis and Ghali in 1991 (35) noted that the most common error made while utilizing traction osteosynthesis for fixation of angle fractures was the tendency to exaggerate the buccal-lingual and superior-inferior angulation of the screw leading to cortical perforations and sub-optimal fixation. Improper countersinking of the osteotomy has also led to several problems, where lack of countersinking resulted in cracks in the cortical bone that support the screw head, while errors of improper countersinking angulation and excessive countersinking was noted which eventually weekend the proximal bony buttress. HBS is a headless screw and we didn't face the opportunity where countersink drill was required.

The compressive feature in the Herbert Bone Screw comes from the differential pitch pattern between its leading and trailing ends. It is a headless screw, that, unlike the lag screw, don't share its compressive property with the outer cortex of the bone; which produces the common complication in lag screw of fracture of the outer cortex of the segment once the compression starts. Although cortical fracture complication can be avoided by countersinking the screw head, the Headless feature of the HBS eliminates the need for this step, giving the chance of a reduced operation time, and gives chance for the screw application to articular surfaces, such as the temporomandibular joint.

Herbert Bone Screw technique requires strict attention to detail in order to achieve a successful therapy. Its technique sensitive management and requires surgical expertise, adequate preoperative assessment of the required screw length and angulation, considered awareness to mandible internal anatomy, training programs and constant reinforcement and guidance in the approach details.

\section{CONCLUSION}

Despite that it is a technique sensitive treatment modality that requires surgical expertise and strict attention to its placement prerequisites, the use of Herbert Bone Screw for mandibular fractures management showed a satisfactory 
and predictable wound and bone healing outcomes. When it is utilized in mandibular angle fractures, it showed superlative rigidity with minimum drilling and hardware requirements.

\section{CONFLICT OF INTEREST}

The authors declare that they have no conflicts of interest

\section{REFERENCES}

1. Erol B, Tanrikulu R, Görgün B. Maxillofacial Fractures. Analysis of demographic distribution and treatment in 2901patients (25-year experience). J Craniomaxillofac Surg. 2004;32:308-13.

2. Gandhi S, Ranganathan L, Solanki M, Mathew G. Pattern of maxillofacial fractures at a tertiary hospital in northern India: a 4-year retrospective study of 718 patients. Dental Traumatol. 2011;27:257-62.

3. Chrcanovic B, Abreu M, Souza L. 1,454 mandibular fractures: A 3-year study in a hospital in Belo Horizonte, Brazil. J CranioMaxillofac Surg. 2012;40:116-23.

4. Ghodke M, Shah S, Bhoyar S. Prevalence of mandibular fractures reported at C.S.M.S.S Dental College, Aurangabad from February 2008 to September 2009. J Int Soc Prev Community Dent. 2013;3:51-8.

5. Brons R, Boering G. Fractures of the mandibular body treated by stable internal fixation: a preliminary report. Journal of oral surgery (American Dental Association: 1965). 1970;28:407-15.

6. Hebert T, Fisher W. Management of the fractured scaphoid using a new bone screw. Plast Reconstr Surg. 1986;78:836.

7. Kirkpatrick L, Feeney B. A simple guide to IBM SPSS: for version 22.0. Students ed. Boston, MA: Cengage Learning; 2015.

8. Kotz S, Balakrishnan N, Read C, vidakovic B. Encyclopedia of statistical sciences 2nd ed. Hoboken, NJ: Wiley-Interscience; 2006.

9. Luhr H. The development of modern osteosynthesis. Mund, Kiefer-und Gesichtschirurgie: MKG. 2000;4(1):S84-90.

10. Moses H, Powers D, Keeler J, Erdmann D. Opportunity cost of surgical management of craniomaxillofacial trauma. Craniomaxillofac Trauma Reconstr. 2016;9:76-81.

11. Sakr K, Farag IA, Zeitoun IM. Review of 509 mandibular fractures treated at the University Hospital, Alexandria, Egypt. Br J Oral Maxillofac Surg. 2006;44:107-11.

12. Mabrouk A, Helal H, Mohamed AR, Mahmoud N. Incidence, etiology, and patterns of maxillofacial fractures in Ain-Shams University, Cairo, Egypt: A 4-year retrospective study. Craniomaxillofac Trauma Reconstr. 2014;7:224-32.

13. Melek LN, Sharara AA. Retrospective study of maxillofacial trauma in Alexandria University: Analysis of 177 cases. Tanta Dent J. 2016;13:28-33.

14. Lee JH, Cho BK, Park WJ. A 4-year retrospective study of facial fractures on Jeju, Korea. J Craniomaxillofac Surg. 2010;38:192-6.

15. Munante-Cardenas JL, Nunes PHF, Passeri LA. Etiology, treatment, and complications of mandibular fractures. J Craniofac Surg. 2015;26:611-5.

16. Teshome A, Andualem G. Two years' retrospective study of maxillofacial trauma at a tertiary center in North West Ethiopia. BMC Res Notes. 2017;10:373-4.

17. Siber S, Matijević M, Sikora M. Assessment of OroMaxillofacial Trauma According to Gender, Age, Cause and Type of the Injury. Acta Stomatol Croat. 2015;49:3407.

18. Bhatnagar A, Bansal V, Kumar S, Mowar A. Comparative analysis of osteosynthesis of mandibular anterior fractures following open reduction using 'stainless steel lag screws and mini plates'. J Maxillofac Oral Surg. 2013;12:133-9.

19. Kotrashetti S, Singh A. Prospective study of treatment outcomes with lag screw versus Herbert screw fixation in mandibular fractures. Int $\mathrm{J}$ Oral Maxillofac Surg. 2017;46:54-8.

20. Lee T, Sawhney R. Miniplate fixation of fractures of the symphyseal and parasymphyseal regions of the mandible: a review of 218 patients. JAMA facial plast surg. 2013;15:121-5

21. Haranal SR, Neeli AS. Titanium lag screw osteosynthesis in the management of mandibular fractures. Int Multidiscip Res J. 2012;2:5-8.

22. Agnihotri A, Prabhu S. A comparative analysis of the efficacy of cortical screws as lag screws and miniplates for internal fixation of mandibular symphyseal region fractures: a randomized prospective study. J Oral Maxillofac Surg. 2014;43:22-8.

23. Boffano P, Roccia F, Gallesio C, Karagozoglu K. Inferior Alveolar Nerve Injuries Associated with Mandibular Fractures at Risk: A Two-Center Retrospective Study. Craniomaxillofac Trauma Reconstr. 2014;7:280-3.

24. Schenkel J, Jacobsen C. Inferior alveolar nerve function after open reduction and internal fixation of mandibular fractures. J Craniomaxillofac Surg. 2016;44:743-8.

25. Balasubramanian S, Kumaravelu C, Elavenil P, Raja VK. Solitary lag-screw fixation for mandibular angle fractures: Prospective study. SRM J Res Dent Sci. 2014;5:180-1.

26. Chhabaria G, Halli R, Chandan S. Evaluation of 2.0-mm Titanium Three-Dimensional Curved Angle Strut Plate in the Fixation of Mandibular Angle Fractures-A Prospective Clinical and Radiological Analysis. Craniomaxillofac Trauma Reconstr. 2014;7:11925.

27. Guimond C, Johnson JV. Fixation of mandibular angle fractures with a 2.0-mm 3-dimensional curved angle strut plate. J Oral Maxillofac Surg. 2005;63:209-14.

28. Shridharani S, Berli J, Manson P, Tufaro A, Rodriguez E. The Role of Postoperative Antibiotics in Mandible Fractures. Ann Plast Surg. 2015;75:353-7.

29. Saman M, Kadakia S, Ducic Y. Postoperative Maxillomandibular Fixation After Open Reduction of Mandible Fractures. JAMA Facial Plast Surg. 2014;16:410.

30. Ellis E. Is lag screw fixation superior to plate fixation to treat fractures of the mandibular symphysis? J Oral Maxillofac Surg. 2012;70:875-82.

31. Pattar P, Shetty S, Degala S. A Prospective Study on Management of Mandibular Angle Fracture. J Maxillofac Oral Surg. 2014;13:592-8.

32. Yamaji T, Ando K, Wolf S, Augat P. The effect of micro movement on callus formation. J Orthop Sci. 2001;6:571-5.

33. Mayrink G, Mendes M, Moreira R, Conto FD. Lag Screw Technique for treating a mandibular angle fracture: case report. Int J Med Surg Sci. 2014;1:263-7

34. Schaaf H, Kaubruegge S, Streckbein P. Comparison of miniplate versus lag-screw osteosynthesis for fractures of the mandibular angle. Oral Surg Oral Med Oral Pathol Oral Radiol Endod. 2011;111:34-40.

35. Ellis E, Ghali GE. Lag screw fixation of mandibular angle fractures. J Oral Maxillofac Surg 1991;49:234-43. 